Article

\title{
Quantum Confinement Effect in Amorphous In-Ga-Zn-O Heterojunction Channels for Thin-Film Transistors
}

\author{
Daichi Koretomo $^{1, *(\mathbb{D} \text {, Shuhei Hamada }}{ }^{2}$, Yusaku Magari ${ }^{1}$ (i) and Mamoru Furuta ${ }^{1,2,3}$ (]) \\ 1 Engineering Course, Kochi University of Technology, Kami, Kochi 782-8502, Japan; \\ 216007n@gs.kochi-tech.ac.jp (Y.M.); furuta.mamoru@kochi-tech.ac.jp (M.F.) \\ 2 Material Science and Engineering Course, Kochi University of Technology, Kami, Kochi 782-8502, Japan; \\ 225109c@gs.kochi-tech.ac.jp \\ 3 Center for Nanotechnology, Research Institute, Kochi University of Technology, Kami, Kochi 782-8502, Japan \\ * Correspondence: 216003c@gs.kochi-tech.ac.jp
}

Received: 12 February 2020; Accepted: 17 April 2020; Published: 20 April 2020

check for updates

\begin{abstract}
Electrical and carrier transport properties in In-Ga-Zn-O thin-film transistors (IGZO TFTs) with a heterojunction channel were investigated. For the heterojunction IGZO channel, a high-In composition IGZO layer (IGZO-high-In) was deposited on a typical compositions IGZO layer (IGZO-111). From the optical properties and photoelectron yield spectroscopy measurements, the heterojunction channel was expected to have the type-II energy band diagram which possesses a conduction band offset $\left(\Delta E_{\mathrm{c}}\right)$ of $\sim 0.4 \mathrm{eV}$. A depth profile of background charge density indicated that a steep $\Delta E_{\mathrm{C}}$ is formed even in the amorphous IGZO heterojunction interface deposited by sputtering. A field effect mobility $\left(\mu_{\mathrm{FE}}\right)$ of bottom gate structured IGZO TFTs with the heterojunction channel (hetero-IGZO TFTs) improved to $\sim 20 \mathrm{~cm}^{2} \mathrm{~V}^{-1} \mathrm{~s}^{-1}$, although a channel/gate insulator interface was formed by an IGZO-111 $\left(\mu_{\mathrm{FE}}=\sim 12 \mathrm{~cm}^{2} \mathrm{~V}^{-1} \mathrm{~s}^{-1}\right)$. Device simulation analysis revealed that the improvement of $\mu_{\mathrm{FE}}$ in the hetero-IGZO TFTs was originated by a quantum confinement effect for electrons at the heterojunction interface owing to a formation of steep $\Delta E_{\mathrm{c}}$. Thus, we believe that heterojunction IGZO channel is an effective method to improve electrical properties of the TFTs.
\end{abstract}

Keywords: oxide semiconductor; thin-film transistor; heterojunction; amorphous; device simulation; quantum confinement

\section{Introduction}

Thin-film transistors (TFTs) based on oxide semiconductors (OSs) have attracted considerable attention for next generation flat-panel displays (FPDs) due to their advantages such as high field effect mobility $\left(\mu_{\mathrm{FE}}\right)$, steep subthreshold swing, and low leakage current [1-9]. Although $\mu_{\mathrm{FE}}$ of the OS TFTs is more than an order of magnitude higher than that of hydrogenated amorphous silicon (a-Si:H) TFTs, further improvement of the $\mu_{\mathrm{FE}}$ has been required for OS TFTs to expand their applications [9-13]. Optimization of compositions of the OSs is an approach to improve $\mu_{\mathrm{FE}}$, such as an increase of In ratio in the OSs $[9,12-15]$. However, it was reported the trade-off between $\mu_{\mathrm{FE}}$ and the reliability of OS TFTs, because an increase of In ratio in the OSs leads to generation defects such as oxygen vacancies [16,17]. As another approach to improve $\mu_{\mathrm{FE}}$ of the OSs, Koike et al. demonstrated a crystalline $\mathrm{ZnO} / \mathrm{ZnMgO}$ heterojunction structure that was confirmed to be an improvement of a Hall mobility [18]. Taniguchi et al. reported a heterojunction channel consisting of polycrystalline In-Sn-O on amorphous In-Ga-Zn-O (IGZO) with a type-II energy band lineup, which attributed an improvement of the $\mu_{\mathrm{FE}}$ to $\sim 20 \mathrm{~cm}^{2} \mathrm{~V}^{-1} \mathrm{~s}^{-1}$ for the TFTs [19]. 
On the other hand, amorphous OSs have an advantage for the spatial uniformity of their transfer characteristics over a large area; thus, the amorphous OS TFTs are promising candidates for large displays. Various types of heterojunction channels, using amorphous OSs such as IGZO/In-Zn-O (IZO), Hf-In-Zn-O/IZO, Zn-Sn-O/IZO and Al-In-Zn-Sn-O/IZO, have been proposed for TFTs [20-24]. These heterojunction TFTs exhibited excellent $\mu_{\mathrm{FE}}$ of over $30 \mathrm{~cm}^{2} \mathrm{~V}^{-1} \mathrm{~s}^{-1}$. The $\mu_{\mathrm{FE}}$ improvements were mainly induced by the IZO layer, with high- $\mu_{\mathrm{FE}}$ formed at the channel/gate insulator (GI) interface. Moreover, the heterojunction channels such as IGZO/In-Zn-O/IGZO and In-Ga-Si-O/IGZO/In-Ga-Si-O have also been reported to improve $\mu_{\mathrm{FE}}[25,26]$. Thus, the heterojunction channels are considered to be an appropriate approach to boost TFT performances even for amorphous OSs. However, the carrier transport properties in the heterojunction channel have not been discussed in detail, despite a key for the improvement of the $\mu_{\mathrm{FE}}$ on the amorphous OS TFTs.

We previously reported about the IGZO TFT with a heterojunction channel consisting of different compositions of the amorphous IGZO films. Based on experimental and simulation results obtained by varying a thickness of the barrier layer of the heterojunction channel, it was found that an IGZO heterojunction channel is an effective method to independently improve electrical properties and the reliability of the TFTs [27]. However, the interface properties of the IGZO heterojunction have not been clearly understood. Furthermore, the influence of a conduction band offset $\left(\Delta E_{\mathrm{c}}\right)$ at the heterojunction interface on the electrical and carrier transport properties has not been analyzed in detail. Thus, it is worth to understand the steepness and $\Delta E_{\mathrm{c}}$ at the amorphous IGZO heterojunction interface formed by sputtering.

In this research, the electrical properties of the heterojunction IGZO TFTs were investigated by varying the thickness of a high-In IGZO (IGZO-high-In) well layer, which was deposited on a typical composition of the IGZO (IGZO-111) barrier layer for the heterojunction. In addition, formation of the heterojunction interface was considered from both of the experimental and theoretical results. $\mu_{\mathrm{FE}}$ of the IGZO TFTs clearly increased, especially in the low gate voltage $\left(V_{\mathrm{GS}}\right)$ region when the heterojunction channel was formed. From a depth analysis of the background charge density, the transition width at the heterojunction interface was estimated to be less than $3 \mathrm{~nm}$. Device simulation analysis revealed that the $\Delta E_{\mathrm{c}}$, which acts as a potential barrier for electrons, strongly affects carrier transport paths in the heterojunction channel, which leads to an improvement in the $\mu_{\mathrm{FE}}$ of the TFTs.

\section{Experimental Methods}

Figure 1a shows a schematic cross-sectional view of the bottom gate structured IGZO TFTs. The IGZO TFTs were fabricated on a heavily doped n-type Si substrate with a 100-nm-thick thermally grown $\mathrm{SiO}_{2}$. The doped n-type $\mathrm{Si}$ substrate and the $\mathrm{SiO}_{2}$ were used as gate electrode and $\mathrm{GI}$, respectively. The IGZO channels were deposited by radio frequency $(\mathrm{RF})$ magnetron sputtering without intentional substrate heating. As shown in Figure $1 b, c$, homogeneous channel layers of the 10-nm-thick IGZO-111 (homo-IGZO-111) and the 10-nm-thick IGZO-high-In (homo-IGZO-high-In) were separately prepared for comparison with the heterojunction channel. The oxygen flow ratio $\left(\mathrm{O}_{2} / \mathrm{Ar}+\mathrm{O}_{2}\right)$ during the depositions were set at $2 \%$ and $49 \%$ for the IGZO-111 and the IGZO-high-In channels, respectively. Deposition pressure and RF power for both the channels were maintained at $0.5 \mathrm{~Pa}$ and $4.4 \mathrm{~W} \mathrm{~cm}^{-2}$, respectively. For the heterojunction channels as shown in Figure 1d, the IGZO-high-In layer was deposited on the 10-nm-thick-IGZO-111 layer (hetero-IGZO) in a chamber without breaking the vacuum. An upper channel thickness of the IGZO-high-In layer was varied from $2.5 \mathrm{~nm}$ to $20 \mathrm{~nm}$, while bottom channel thickness of the IGZO-111 layer was maintained at $10 \mathrm{~nm}$ to apply constant electric field at the heterojunction interface. Note here that the deposition conditions for each layer in the heterojunction channel were the same as the homogeneous channels. After formation of the IGZO channel using a shadow mask, a $\mathrm{SiO}_{2}$ passivation layer $(200 \mathrm{~nm})$ was grown by plasma-enhanced chemical vapor deposition at $180{ }^{\circ} \mathrm{C}$ using tetraethoxysilane and $\mathrm{O}_{2}$ as precursors. After opening contact holes by photolithography and dry etching, In-Sn-O source/drain electrodes were deposited 
by sputtering through a shadow mask. Finally, the IGZO TFTs were annealed at $350{ }^{\circ} \mathrm{C}$ in ambient air for one hour. Channel width and length were $1000 \mu \mathrm{m}$ and $690 \mu \mathrm{m}$, respectively $(\mathrm{W} / \mathrm{L}=1000 / 690 \mu \mathrm{m})$.

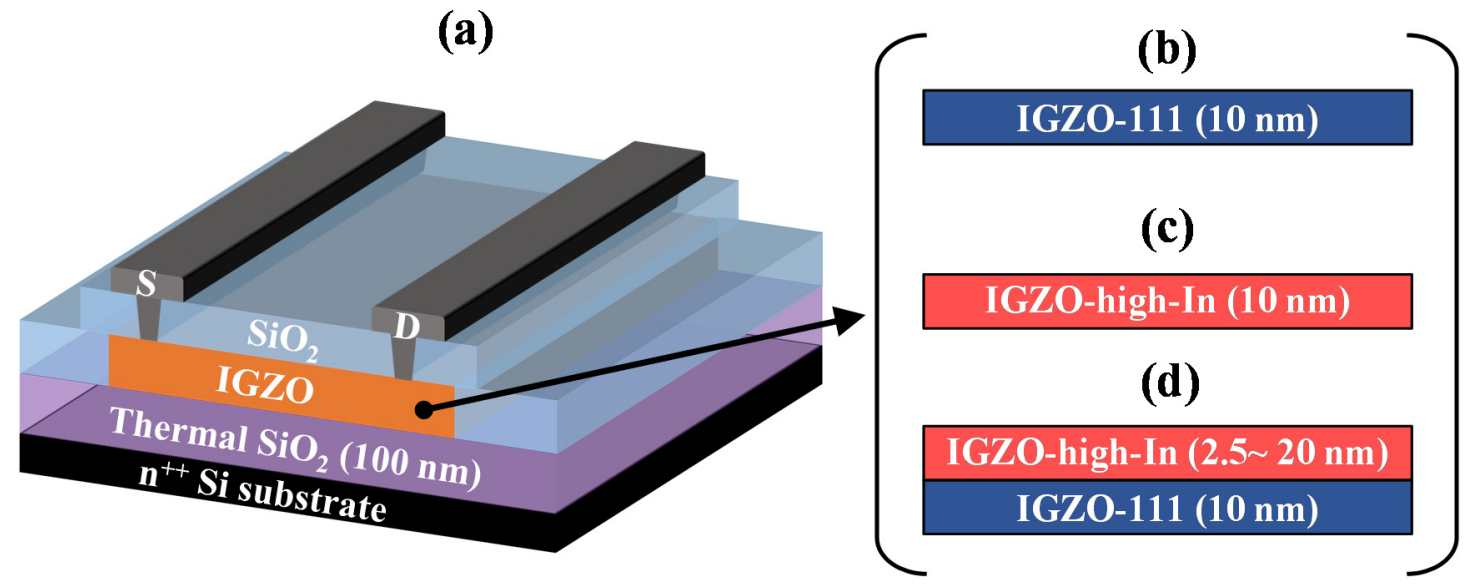

Figure 1. (a) Schematic cross-sectional view of the bottom gate structured $\mathrm{In}-\mathrm{Ga}-\mathrm{Zn}-\mathrm{O}$ thin-film transistor (IGZO TFT). Channel structures of the (b) homogenous typical composition of the IGZO (homo-IGZO-111), (c) homogenous high-In IGZO (homo-IGZO-high-In), and (d) heterojunction IGZO (hetero-IGZO).

\section{Results and Discussion}

\subsection{Crystallinity of IGZO films}

First, the crystallinity of each IGZO layer was evaluated by grazing incidence X-ray diffraction (GIXRD, Rigaku Corp., ATX-G, Tokyo, Japan) using $\mathrm{Cu}-\mathrm{K} \alpha$ radiation with the $\mathrm{X}$-ray incident beam angle $(\omega)$ of $0.35^{\circ}$. Figure 2 shows GIXRD patterns of the (a) IGZO-111 and (b) IGZO-high-In layers as a function of annealing temperature. Both the IGZO-111 and high-In layer showed crystallization at the annealing temperature of $700-800{ }^{\circ} \mathrm{C}$. The XRD peaks obtained from IGZO-111 after $800{ }^{\circ} \mathrm{C}$ attributed to crystalline IGZO, whereas that of IGZO-high-In layer mainly related to crystalline $\mathrm{In}_{2} \mathrm{O}_{3}$ due to high In ratio in the IGZO $[28,29]$. On the other hand, both the IGZO-111 and the IGZO-high-In layers retained their amorphous phase at annealing temperatures lower than $600{ }^{\circ} \mathrm{C}$.
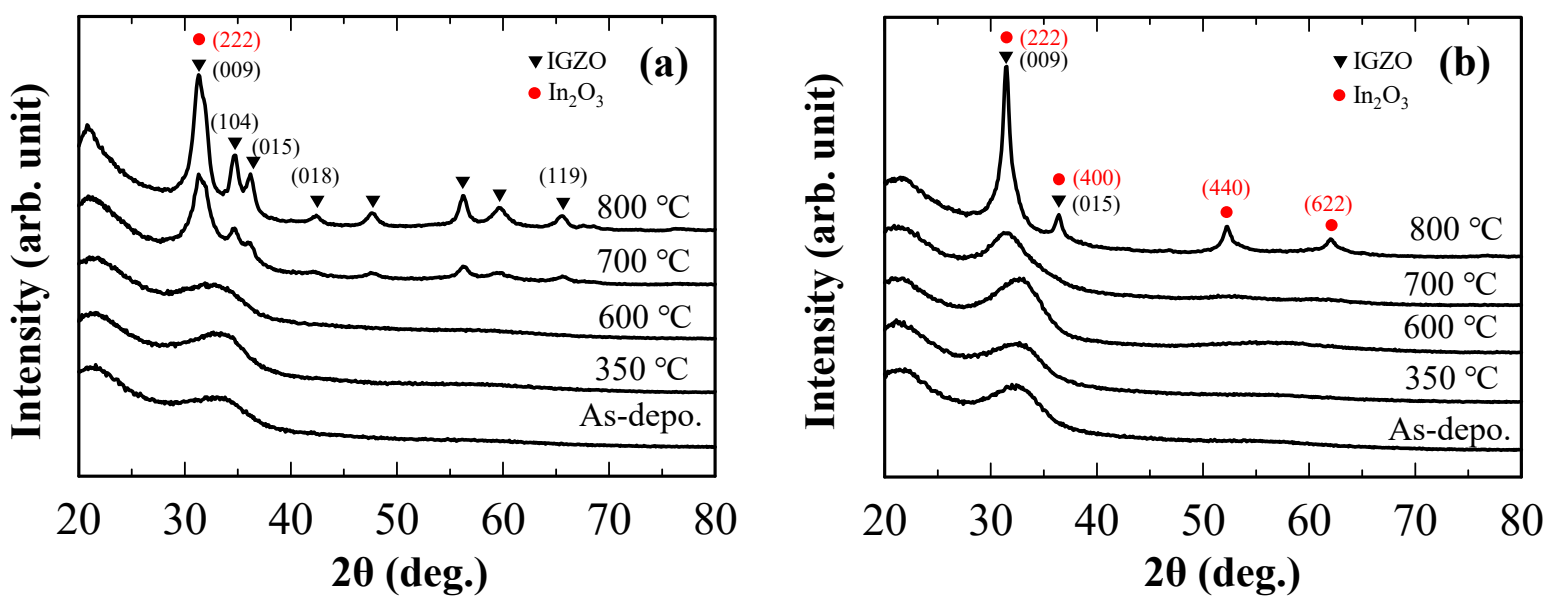

Figure 2. Grazing incidence X-ray diffraction (GIXRD) patterns of (a) IGZO-111 and (b) IGZO-high-In layers as a function of annealing temperature. Annealing was carried out in air for one hour. 


\subsection{Band Alignment and Steepness at Heterojunction Interface}

Optical band gap $\left(E_{\mathrm{g}}\right)$ was estimated by Tauc plot. Valence band maximum (VBM) of the IGZO films was estimated from an ionization potential $\left(I_{p}\right)$, which was measured by photoelectron yield spectroscopy (Bunkoukeiki, BIP-KV202GD, Tokyo, Japan). Figure 3a,b show the Tauc plots and photoemission yield of the IGZO layers. The optical band gaps of the IGZO-111 and the IGZO-high-In layers were estimated to be $\sim 3.1$ and $\sim 2.8 \mathrm{eV}$, respectively. VBMs of the IGZO-111 and the IGZO-high-In layers were $\sim 7.4$ and $\sim 7.5 \mathrm{eV}$, respectively. Since conduction band minimum (CBM) of IGZO mainly consists of In-5s orbitals [30-32], CBM of the IGZO layer would be influence by an In ratio. From these results, the energy band diagram of the IGZO-111 and the IGZO-high-In layers was shown in Figure 3c, suggesting that a $\Delta E_{\mathrm{c}}$ of $\sim 0.4 \mathrm{eV}$ might be formed at the heterojunction interface.
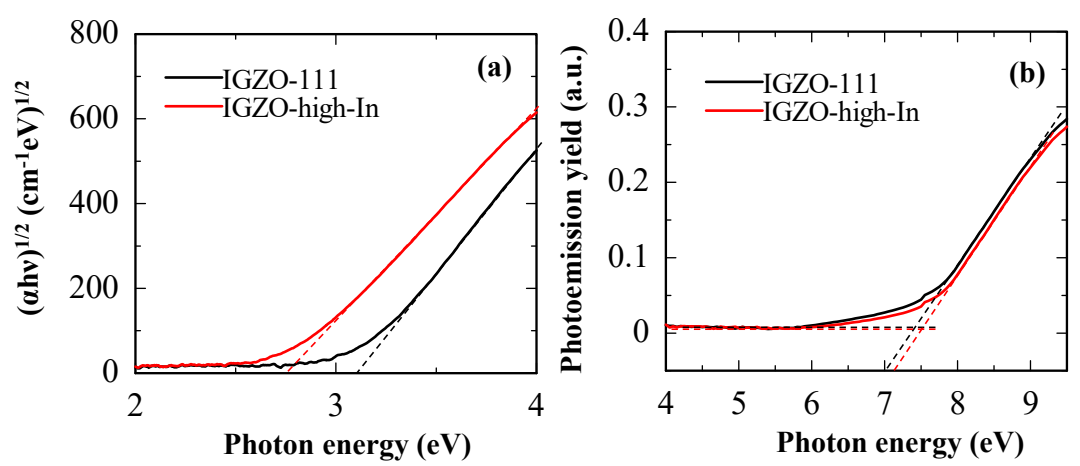

(c)

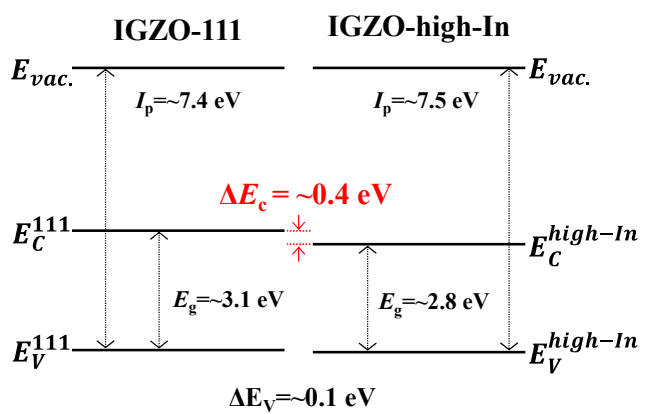

Figure 3. (a) Tauc plots and (b) photoemission yield of the IGZO-111 and the IGZO-high-In layers after annealing at $350{ }^{\circ} \mathrm{C}$ in in ambient air for one hour. (c) Energy band diagrams of the IGZO-111 and the IGZO-high-In layers.

To confirm steepness at the heterojunction interface, the depth profile of background charge density $\left(N_{\mathrm{bg}}\right)$ was evaluated by a Schottky diode (SD) with the heterojunction channel as shown in Figure 4a. Detailed fabrication process of the IGZO SD was reported elsewhere [33]. For the SD with the heterojunction channel, channel thicknesses for the each IGZO layer were set at $30 \mathrm{~nm}$. Carrier density $\left(n_{\mathrm{e}}\right)$ of the IGZO-111 was set at $\sim 1 \times 10^{17} \mathrm{~cm}^{-3}$ to obtain good Schottky contact, while that of the IGZO-high-In was set at $\sim 3 \times 10^{18} \mathrm{~cm}^{-3}$ to enhance the difference of $N_{\mathrm{bg}}$ at the heterojunction interface. The $N_{\text {bg }}$ was estimated using an equation as shown below [34,35];

$$
N_{b g}=\frac{2}{q \varepsilon_{0} \varepsilon_{s}}\left[\frac{-1}{\partial\left(1 / C_{s}^{2}\right) / \partial V}\right]
$$

where $\varepsilon_{\mathrm{s}}$ and $C_{\mathrm{s}}$ were permittivity and capacitance per unit area of the IGZO, respectively. The $C_{\mathrm{s}}$ was measured using Agilent E4980A LCR meter (California, CA, USA). Figure 4a shows $1 / C_{s}{ }^{2}-V$ characteristic of the Schottky diode at $1 \mathrm{kHz}$. The $1 / C_{S}^{2}$ values gradually decreased when the voltage 
applied from -1.5 to $0 \mathrm{~V}$. This result indicates that the heterojunction channel was not fully depleted at the negative voltage of $-1.5 \mathrm{~V}$. As the voltage exceeded $0 \mathrm{~V}$, the $1 / C_{s}{ }^{2}$ values decreased steeply.

(a)

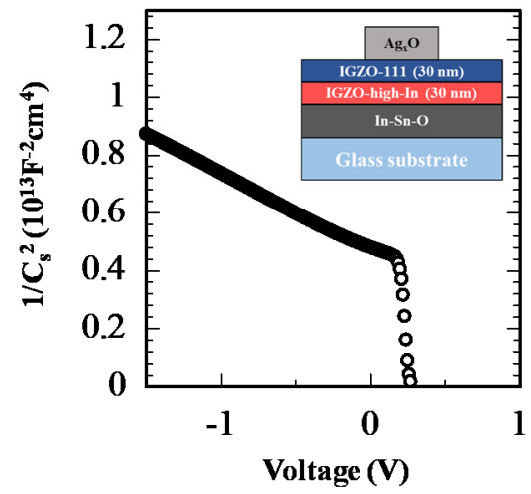

(b)

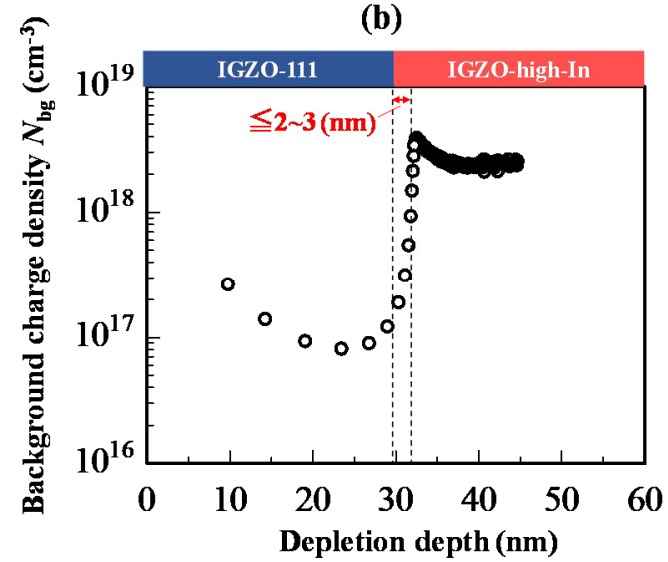

Figure 4. (a) $1 / C_{s}{ }^{2}-V$ characteristic of the Schottky diode at $1 \mathrm{kHz}$. Inset is a schematic cross-sectional view of the Schottky diode with the heterojunction IGZO. The heterojunction IGZO was annealed at $350{ }^{\circ} \mathrm{C}$ in ambient air for one hour before deposition of an $\mathrm{Ag}_{x} \mathrm{O}$ electrode. (b) Depth profile of $N_{\mathrm{bg}}$ calculated using the $1 / C_{s}{ }^{2}-V$ characteristic. The depth $x=0 \mathrm{~nm}$ corresponds to the $\operatorname{Ag}_{x} \mathrm{O} / \mathrm{IGZO}-111$ interface.

From the $1 / C_{s}{ }^{2}-V$ characteristic, depth profile of $N_{\mathrm{bg}}$ in the heterojunction channel was calculated as shown in Figure $4 \mathrm{~b}$. The $N_{\mathrm{bg}}$ of IGZO-111 layer at the depletion depth from 10 to $30 \mathrm{~nm}$ showed approximately $1 \times 10^{17} \mathrm{~cm}^{-3}$, and the $N_{\mathrm{bg}}$ of IGZO-high-In steeply increased to $\sim 2 \times 10^{18} \mathrm{~cm}^{-3}$ when the depletion depth exceeds $30 \mathrm{~nm}$. The region where the transition of $N_{\mathrm{bg}}$ occurred corresponded to the heterojunction interface region. Moreover, the transition width of $N_{\mathrm{bg}}$ at the heterojunction interface was estimated to be less than $3 \mathrm{~nm}$. This result indicated that steep $\Delta E_{\mathrm{c}}$ would be formed at the heterojunction interface even though both the amorphous IGZO layers were deposited by sputtering.

\subsection{TFT Characteristics}

Electrical properties of the homogeneous IGZO (homo-IGZO) TFTs were first examined as references for comparison with the heterojunction IGZO (hetero-IGZO) TFTs. Transfer characteristics of the TFTs were measured in dark using precision semiconductor parameter analyzers (Agilent 4156C and $4156 \mathrm{~A}$, California, CA, USA). The threshold voltage $\left(V_{\mathrm{th}}\right)$ was defined as the $V_{\mathrm{GS}}$ required to obtain the drain current $\left(I_{\mathrm{DS}}\right)$ of $1 \mathrm{nA}$ in a linear region. The hysteresis $\left(V_{\mathrm{H}}\right)$ was extracted from $V_{\text {th }}$ difference between forward and reverse characteristics. The $\mu_{\mathrm{FE}}$ was calculated from a linear region using the following equation;

$$
\mu_{F E}=\frac{g_{m}}{\frac{W}{L} C_{i} V_{D S}}
$$

where $g_{\mathrm{m}}, C_{\mathrm{i}}$, and $V_{\mathrm{DS}}$ denote transconductance, capacitance of GI per unit area, and drain voltage, respectively.

Figure 5 shows the transfer characteristics of the homo-IGZO-111 and the IGZO-high-In TFTs. Owing to the optimization of a channel thickness and an oxygen flow ratio during the channel deposition [36,37], $V_{\text {th }}$ of the homo-IGZO-111 and the IGZO-high-In TFTs were close to zero. From $\mu_{\mathrm{FE}}-V_{\mathrm{GS}}$ curve shown in Figure $5, \mu_{\mathrm{FE}}$ of both the homo-IGZO TFTs increased with increasing $V_{\mathrm{GS}}$. The homo-IGZO-high-In TFT exhibited $\mu_{\mathrm{FE}}$ of $22.9 \mathrm{~cm}^{2} \mathrm{~V}^{-1} \mathrm{~s}^{-1}$, which is approximately two times higher $\mu_{\mathrm{FE}}$ than that of the homo-IGZO-111 TFT $\left(12.4 \mathrm{~cm}^{2} \mathrm{~V}^{-1} \mathrm{~s}^{-1}\right)$. This result indicates that $\mu_{\mathrm{FE}}$ improvement of the homo-IGZO-high-In TFT was originated by a high-In composition, since large spherical In 5s orbitals mainly form carrier transport paths [26,30,31]. 

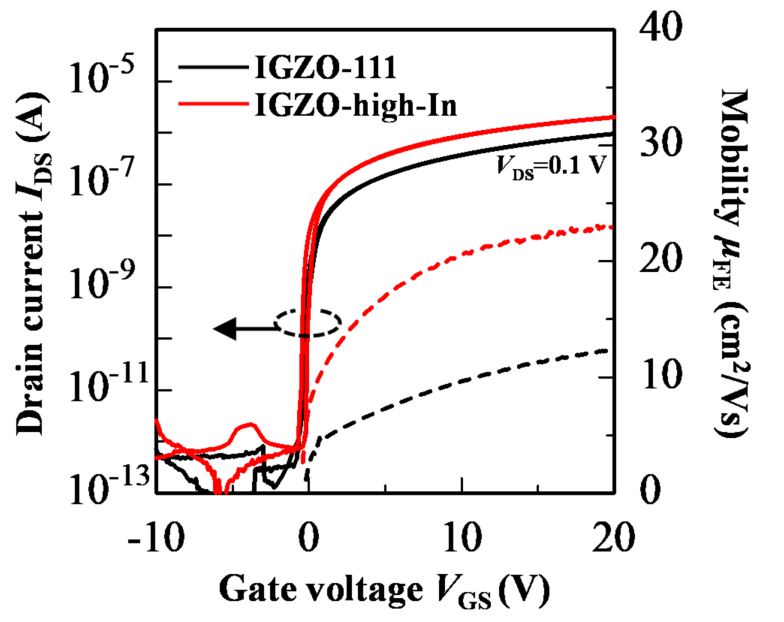

Figure 5. Transfer characteristics of the homo-IGZO-111 and the IGZO-high-In TFTs $\left(V_{\mathrm{DS}}=0.1 \mathrm{~V}\right.$, $\mathrm{W} / \mathrm{L}=1000 / 690 \mu \mathrm{m})$.

Next, electrical properties of the hetero-IGZO TFTs consisting of the IGZO-high-In on the IGZO-111 were explored. Figure 6 shows the transfer characteristic and $\mu_{\mathrm{FE}}-V_{\mathrm{GS}}$ curves of the hetero-IGZO TFTs with various IGZO-high-In thicknesses. The electrical properties of the hetero-IGZO TFTs summarized in Table 1. The hetero-IGZO TFT with a 2.5-nm-thick upper IGZO-high-In layer showed a $\mu_{\mathrm{FE}}$ of $9.9 \mathrm{~cm}^{2}$ $\mathrm{V}^{-1} \mathrm{~s}^{-1}$, which is almost the same $\mu_{\mathrm{FE}}$ as homo-IGZO-111 TFT. In contrast, $\mu_{\mathrm{FE}}$ of the hetero-IGZO TFT significantly improved to $17.2 \mathrm{~cm}^{2} \mathrm{~V}^{-1} \mathrm{~s}^{-1}$ when the upper IGZO-high-In thickness increased from 2.5 to $5.0 \mathrm{~nm}$. The hetero-IGZO TFT with a 10-nm-thick upper IGZO-high-In layer exhibited a $\mu_{\mathrm{FE}}$ of $19.6 \mathrm{~cm}^{2} \mathrm{~V}^{-1} \mathrm{~s}^{-1}$. When the upper IGZO-high-In thickness further increased to more than $10 \mathrm{~nm}$, the $\mu_{\mathrm{FE}}$ saturated to about $21 \mathrm{~cm}^{2} \mathrm{~V}^{-1} \mathrm{~s}^{-1}$, while $V_{\text {th }}$ started to shift in the negative $V_{\mathrm{GS}}$ direction. It can be considered that higher negative $V_{\mathrm{GS}}$ is required to deplete the channel when the upper IGZO-high-In thickness increase, because the carrier density of the IGZO-high-In layer is higher than that of the IGZO-111 layer. Note here that the $\mu_{\mathrm{FE}}$ mainly improved in low- $V_{\mathrm{GS}}$ region $\left(V_{\mathrm{GS}} \leqq 10 \mathrm{~V}\right)$, and it decreased to a similar value as the homo-IGZO-111 TFT at $V_{\mathrm{GS}}$ of $20 \mathrm{~V}$. As a result, the $\mu_{\mathrm{FE}}-V_{\mathrm{GS}}$ curves showed a peak at $V_{\mathrm{GS}}$ below $10 \mathrm{~V}$. The $\mu_{\mathrm{FE}}$ improvement would be caused by carrier transport in the high-In layer owing to a formation of steep $\Delta E_{\mathrm{c}}$ at the heterojunction interface. To understand an origin of the $\mu_{\mathrm{FE}}$ improvement in the hetero-IGZO TFTs, carrier transport in the heterojunction channel is discussed based on the results obtained using a device simulation (Atlas, Silvaco Inc., California, CA, USA).
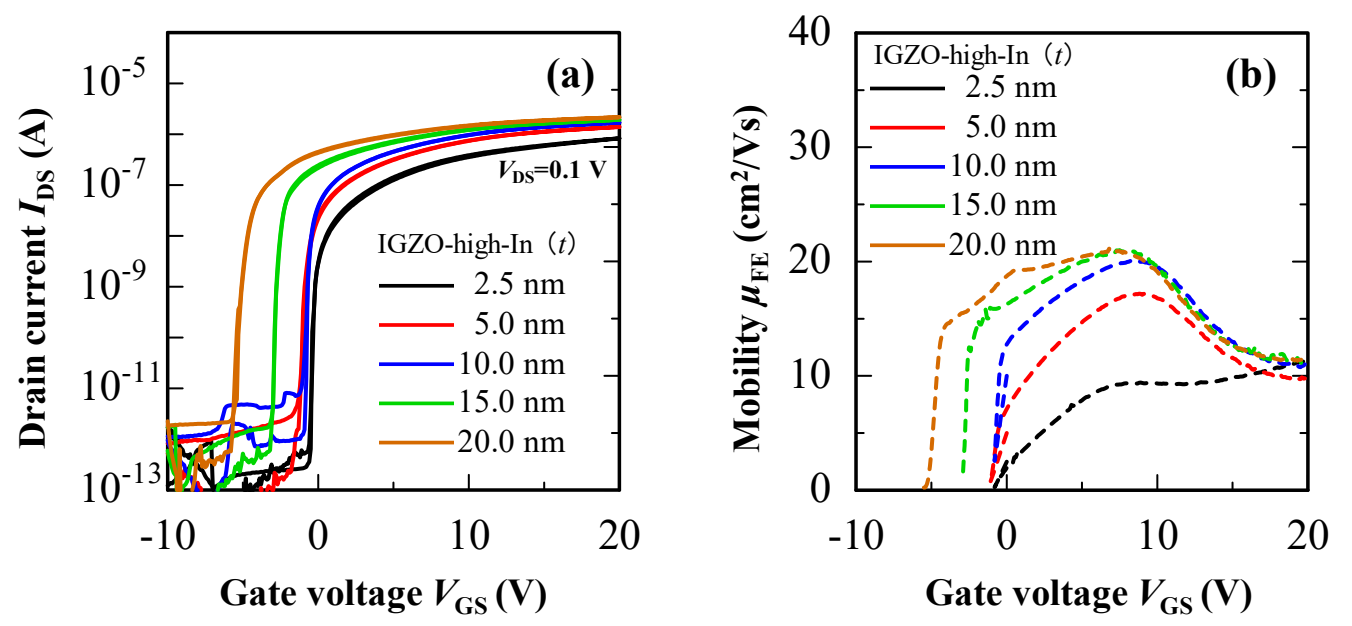

Figure 6. (a) Transfer characteristics and (b) $\mu_{\mathrm{FE}}-V_{\mathrm{GS}}$ curves of the hetero-IGZO TFTs with various thickness of the IGZO-high-In layer ( $\left.V_{\mathrm{DS}}=0.1 \mathrm{~V}, \mathrm{~W} / \mathrm{L}=1000 / 690 \mu \mathrm{m}\right)$. 
Table 1. Summary of electrical properties of the hetero-IGZO TFTs with the various IGZO-high-In thicknesses.

\begin{tabular}{cccccc}
\hline IGZO-High-In Thickness & $\mathbf{2 . 5} \mathbf{~ n m}$ & $\mathbf{5} \mathbf{~ m}$ & $\mathbf{1 0} \mathbf{~ m}$ & $\mathbf{1 5} \mathbf{~ n m}$ & $\mathbf{2 0} \mathbf{~ m}$ \\
\hline IGZO-111 Thickness & & \multicolumn{5}{c}{$\mathbf{1 0} \mathbf{~ m}$} \\
\hline$\mu_{\mathrm{FE}}\left(\mathrm{cm}^{2} \mathrm{~V}^{-1} \mathrm{~s}^{-1}\right)$ & 9.9 & 17.2 & 19.6 & 21.8 & 21.3 \\
S.S. $(\mathrm{V} /$ dec. $)$ & 0.10 & 0.10 & 0.10 & 0.12 & 0.15 \\
$V_{\text {th }}(\mathrm{V})$ & 0 & -0.9 & -0.9 & -3.3 & -5.1 \\
$V_{\mathrm{H}}(\mathrm{V})$ & 0.0 & 0.0 & 0.0 & 0.0 & 0.0 \\
\hline
\end{tabular}

Meanwhile, there is no $V_{\mathrm{H}}$ in the hetero-IGZO TFTs, although the homo-IGZO-high-In TFT showed $V_{\mathrm{H}}$ of $+1.2 \mathrm{~V}$ as shown in Figure 5 . These results indicate that the hetero-TFTs showed high $\mu_{\mathrm{FE}}$ with an improvement of reliability. The reliability results of the IGZO TFTs are discussed in the Figure S1 of Supplementary Information.

\subsection{Device Simulation}

To understand carrier transport in the hetero-IGZO TFTs, device simulation was carried out using device simulator, Atlas. For the model of IGZO TFTs, a $n_{\mathrm{e}}$-dependent mobility $\left(\mu_{\mathrm{d}}\right)$ model with the density of states (DOSs) model was proposed by K. Abe [36]. The $n_{\mathrm{e}}$-dependent $\mu_{\mathrm{d}}$ model is given by the following equations [36];

$$
\begin{gathered}
\mu_{d}=\mu_{d 0}(1+\gamma)\left(\frac{n_{e}}{n_{C R}}\right) \\
\gamma=\frac{T_{\gamma}}{T}+\gamma_{0}
\end{gathered}
$$

where $\mu_{\mathrm{d} 0}$ is the intrinsic mobility and $n_{\mathrm{CR}}$ is the critical carrier density, and $\gamma$ is the index parameter.

The simulation parameters, namely, band gap, electron affinity, and $n_{\mathrm{e}}$ dependences of $\mu_{\mathrm{d}}$ were defined by the experimental results for both the IGZO layers (see Figure S2, Supplementary Information). The transfer characteristics of the homo-IGZO TFTs shown in Figure 5 were first reproduced to determine the DOSs in each IGZO layer [38-40]. The extracted parameters in both the IGZO models are shown in Table 2. Then, transfer characteristic of the hetero-IGZO TFT with a 10-nm-thick upper high-In layer was reproduced using the same DOSs as homo-IGZO TFTs. Note here that the contacts between S/D electrodes and IGZO back channel were assumed to be ohmic [41].

From above mentioned experimental results, the cause of the $\mu_{\mathrm{FE}}$ improvement in the hetero-IGZO TFTs is considered to be related to a formation of $\Delta E_{\mathrm{c}}$ at the heterojunction interface. To prove the hypothetical origin of the $\mu_{\mathrm{FE}}$ improvement, influence of the $\Delta E_{\mathrm{c}}$ on carrier transport paths of the hetero-IGZO TFT with a 10-nm-thick upper IGZO-high-In layer was analyzed by a device simulation. Figure 7a,b show transfer characteristics and $\mu_{\mathrm{FE}}-V_{\mathrm{GS}}$ curves of the hetero-IGZO TFTs as a function of $\Delta E_{\mathrm{c}}$ formed at the heterojunction interface. The drain current and $\mu_{\mathrm{FE}}$ of the hetero-IGZO TFTs increased with increasing the $\Delta E_{\mathrm{c}}$. When the $\Delta E_{\mathrm{c}}$ was set at zero eV, the $\mu_{\mathrm{FE}}$ of the hetero-IGZO TFT gradually increased with increasing $V_{\mathrm{GS}}$ and showed approximately $10 \mathrm{~cm}^{2} \mathrm{~V}^{-1} \mathrm{~s}^{-1}$ at the $V_{\mathrm{GS}}$ of $20 \mathrm{~V}$. In contrast, the $\mu_{\mathrm{FE}}$ in low- $V_{\mathrm{GS}}$ region improved when the value of $\Delta E_{\mathrm{c}}$ increased. Moreover, the $V_{\mathrm{GS}}$ value obtained at maximum $\mu_{\mathrm{FE}}$ shifted to a positive $V_{\mathrm{GS}}$ direction when the $\Delta E_{\mathrm{c}}$ increased from 0.1 to $0.45 \mathrm{eV}$. The experimental $\mu_{\mathrm{FE}}-V_{\mathrm{GS}}$ curve could be reproduced well when the $\Delta E_{\mathrm{c}}$ was set at $0.45 \mathrm{eV}$. Thus, it was confirmed that the $\Delta E_{\mathrm{c}}$ at the heterojunction interface strongly influenced $\mu_{\mathrm{FE}}$ of the hetero-IGZO TFT especially in low- $V_{\mathrm{GS}}$ region. 
Table 2. Extracted parameters in the homo-IGZO-111 and the IGZO-high-In models.

\begin{tabular}{|c|c|c|c|c|}
\hline \multirow{2}{*}{ Symbol } & \multicolumn{2}{|c|}{ Value (IGZO) } & \multirow{2}{*}{ Unit } & \multirow{2}{*}{ Description } \\
\hline & -111 & -High-In & & \\
\hline$N_{\mathrm{C}}$ & $5.0 \times 10^{18}$ & $5.0 \times 10^{18}$ & $\mathrm{~cm}^{-3}$ & Effective conduction band density of states \\
\hline$\mu_{\mathrm{d} 0}$ & 14 & 30 & $\mathrm{~cm}^{2} \mathrm{~V}^{-1} \mathrm{~s}^{-1}$ & Intrinsic electron mobility \\
\hline$n_{\mathrm{CR}}$ & $1.0 \times 10^{20}$ & $1.0 \times 10^{20}$ & $\mathrm{~cm}^{-3}$ & Critical electron density \\
\hline$T_{\gamma}$ & 178.4 & 178.4 & K & $\gamma$ temperature \\
\hline$\gamma_{0}$ & -0.31 & -0.31 & - & Gamma at $1 / \mathrm{T}=0$ \\
\hline$W_{\text {ga }}$ & 0.7 & 1.2 & $\mathrm{eV}$ & Decay energy of acceptor-like Gaussian trap \\
\hline$W_{\mathrm{gd}}$ & 0.12 & 0.12 & $\mathrm{eV}$ & Decay energy of donor-like Gaussian trap \\
\hline$E_{\mathrm{ga}}$ & 0 & 0 & $\mathrm{eV}$ & Mean energy of Gaussian acceptor-like trap \\
\hline$E_{\mathrm{gd}}$ & 2.6 & 2.2 & $\mathrm{eV}$ & Mean energy of Gaussian donor-like trap \\
\hline$N_{\text {ga }}$ & $1.5 \times 10^{17}$ & $1.5 \times 10^{17}$ & $\mathrm{~cm}^{-3} \mathrm{ev}^{-1}$ & Peak density of Gaussian acceptor-like trap \\
\hline$N_{\mathrm{gd}}$ & $1.3 \times 10^{17}$ & $1.3 \times 10^{17}$ & $\mathrm{~cm}^{-3} \mathrm{ev}^{-1}$ & Peak density of Gaussian donor-like trap \\
\hline$N_{\text {ta }}$ & $1.0 \times 10^{19}$ & $1.0 \times 10^{19}$ & $\mathrm{~cm}^{-3} \mathrm{ev}^{-1}$ & Acceptor-like tail trap density \\
\hline$N_{\mathrm{td}}$ & $3.0 \times 10^{19}$ & $3.0 \times 10^{19}$ & $\mathrm{~cm}^{-3} \mathrm{ev}^{-1}$ & Donor-like tail trap density \\
\hline$W_{\text {ta }}$ & 0.01 & 0.01 & $\mathrm{eV}$ & Slope of acceptor-like tail trap \\
\hline$W_{\mathrm{td}}$ & 0.1 & 0.1 & $\mathrm{eV}$ & Slope of donor-like tail trap \\
\hline
\end{tabular}
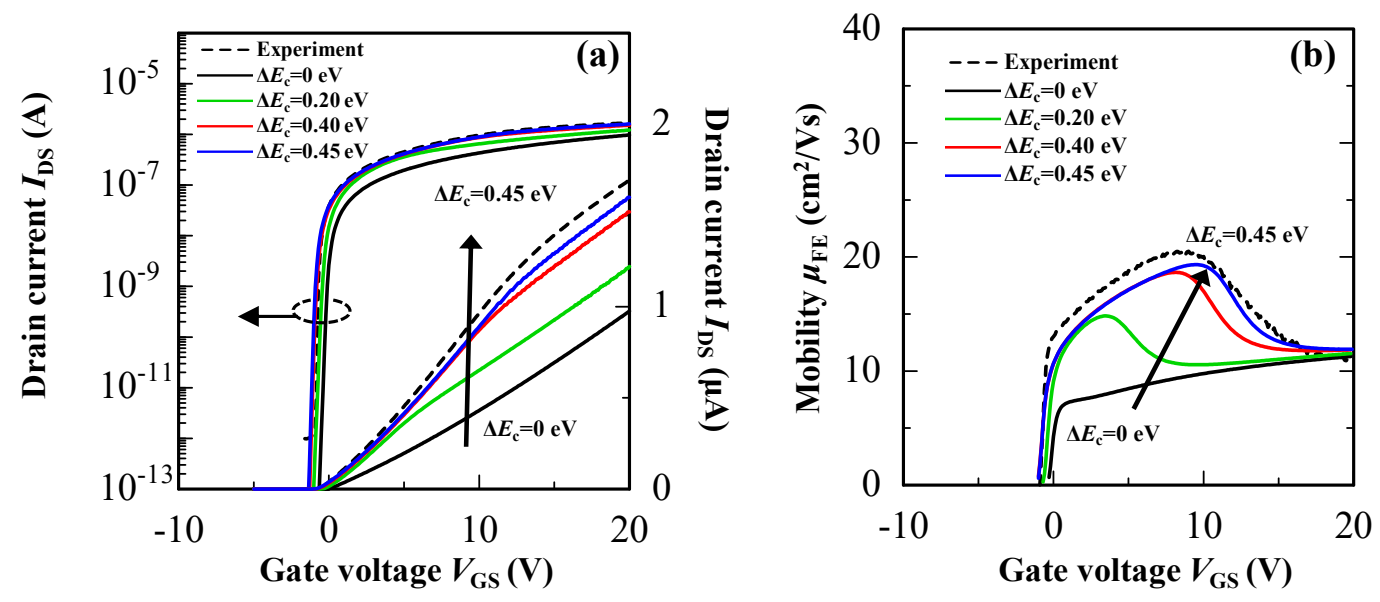

Figure 7. Simulation results of (a) transfer characteristics and (b) $\mu_{\mathrm{FE}}-V_{\mathrm{GS}}$ curves of the hetero-IGZO TFTs with different $\Delta E_{\mathrm{c}}$. The broken line is an experimental result of the hetero-IGZO TFT.

To clarify influence of the $\Delta E_{\mathrm{c}}$ on carrier transport properties, drain current densities in the hetero-IGZO TFTs with different $\Delta E_{\mathrm{c}}$ were also analyzed by a device simulation as shown in Figure 8. The drain current densities in the hetero-IGZO TFTs were extracted at the applied $V_{\mathrm{GS}}$ of $10 \mathrm{~V}$ and $V_{\mathrm{DS}}$ of $0.1 \mathrm{~V}$. For the hetero-IGZO TFT with a $\Delta E_{\mathrm{c}}$ of zero $\mathrm{eV}$, the drain current densities increased at the IGZO-111/GI interface. Therefore, the hetero-IGZO TFT without $\Delta E_{\mathrm{c}}$ exhibited almost the same $\mu_{\mathrm{FE}}$ as homo-IGZO-111 TFT. On the other hand, the drain current densities at the IGZO-111/GI interface reduced and that at the heterojunction interface increased with increasing the $\Delta E_{\mathrm{c}}$. These results indicate that the carrier transport in the hetero-IGZO-TFTs changed from the IGZO-111/GI interface to the heterojunction interface owing to a quantum confinement effect for electrons when the $\Delta E_{\mathrm{c}}$ was formed at the heterojunction interface. Thus, the experimental and device simulation results clarified that the improvement of $\mu_{\mathrm{FE}}$ in the hetero-IGZO TFTs was mainly caused by a quantum confinement effect for electrons, which was induced by $\Delta E_{\mathrm{c}}$ at the heterojunction interface. 
(a)
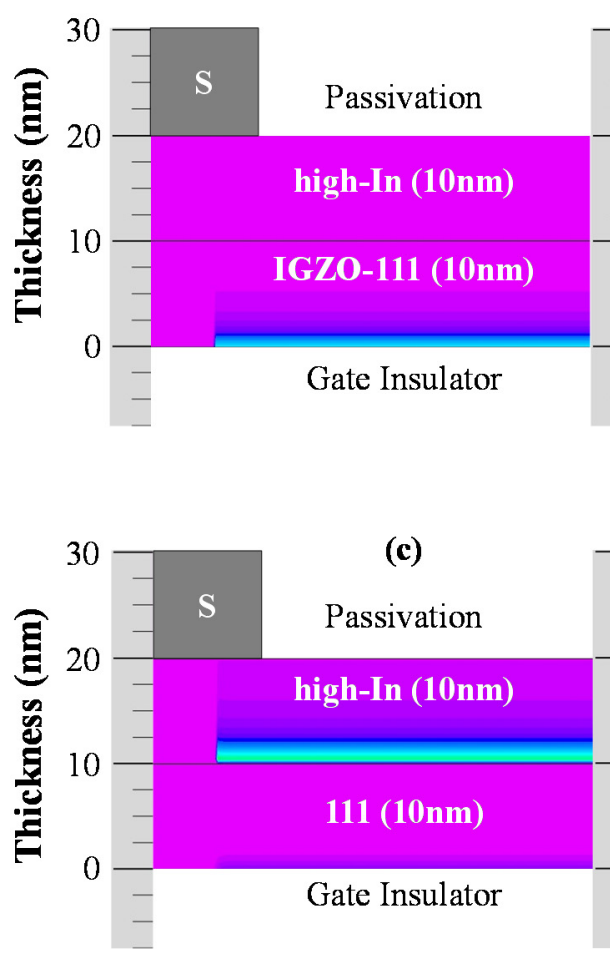

(b)

Passivation

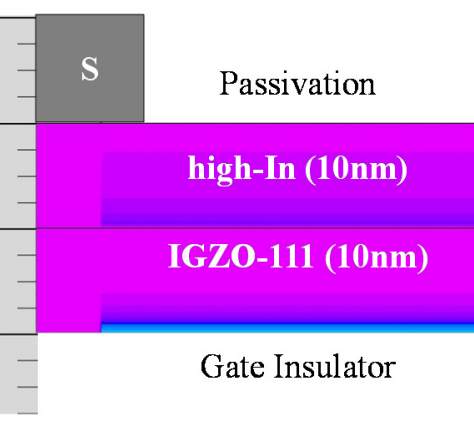

(d)

Passivation

high-In (10nm)

$111(10 \mathrm{~nm})$

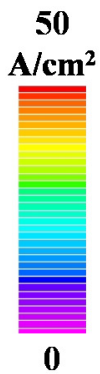

$\mathbf{A} / \mathbf{c m}^{2}$

Figure 8. Drain current densities in the hetero-IGZO TFTs with $\Delta E_{\mathrm{c}}$ of the $(\mathbf{a}) 0 \mathrm{eV},(\mathbf{b}) 0.2 \mathrm{eV},(\mathbf{c}) 0.4 \mathrm{eV}$, and (d) $0.45 \mathrm{eV}$. The insert is the color coding for the drain current density at $V_{\mathrm{GS}}=+10 \mathrm{~V}\left(V_{\mathrm{DS}}=0.1 \mathrm{~V}\right)$.

\section{Conclusions}

We investigated the electrical properties of the TFTs with the IGZO heterojunction channels consisting of different compositions. The heterojunction channel was formed to deposit a high-In composition IGZO layer on an IGZO-111 layer. From band alignment analyses, type-II energy band diagram was expected to form at the heterojunction interface with a $\Delta E_{\mathrm{c}}$ of $\sim 0.4 \mathrm{eV}$. In addition, a depth profile of background charge density indicated that a steep $\Delta E_{\mathrm{c}}$ was formed at the amorphous IGZO heterojunction interface formed by sputtering. The $\mu_{\mathrm{FE}}$ of the IGZO TFT with the heterojunction channel improved to $20.1 \mathrm{~cm}^{2} \mathrm{~V}^{-1} \mathrm{~s}^{-1}$, and its $\mu_{\mathrm{FE}}-V_{\mathrm{GS}}$ curve exhibited a maximum value at applying $V_{\mathrm{GS}}$ of $\sim 10 \mathrm{~V}$. The experimental $\mu_{\mathrm{FE}}-V_{\mathrm{GS}}$ curve could be reproduced well by a device simulation when the $\Delta E_{\mathrm{c}}$ was assumed at the heterojunction interface. Moreover, the device simulation results indicated that the carrier transport in the hetero-IGZO-TFTs changed from the IGZO-111/GI interface to the heterojunction interface owing to a quantum confinement for electrons when the $\Delta E_{\mathrm{c}}$ was formed at the heterojunction interface. Thus, we believe that heterojunction IGZO channel provides an effective method to improve electrical properties of the TFTs.

Supplementary Materials: The following are available online at http://www.mdpi.com/1996-1944/13/8/1935/s1, Figure S1. Changes of transfer characteristics of the (a) homo-IGZO-111, (b) homo-IGZO-high-In, and (c) hetero-IGZO TFTs as a function of PBTS time. The thickness of heterojunction channel is IGZO-high-In/IGZO-111 $=10 / 10 \mathrm{~nm}$. (d) Relationship between $\mu_{\mathrm{FE}}$ and $\Delta V_{\mathrm{th}}$ after the PBTS of $10 \mathrm{ks}$ of the homo- and hetero-IGZO TFTs. The stress temperature was $60{ }^{\circ} \mathrm{C}$ and stress gate bias was $+20 \mathrm{~V}$, respectively, Figure S2. $n_{\mathrm{e}}$ dependences of measured Hall mobilities (circles) and calculated mobilities (lines) of the IGZO-111 and the IGZO-high-In films.

Author Contributions: Conceptualization, D.K. and M.F.; methodology, D.K., S.H., Y.M. and M.F.; formal analysis, D.K. and S.H.; investigation, D.K. and S.H.; resources; M.F.; date curation; D.K., S.H., Y.M. and M.F.; writing —original draft preparation, D.K. and M.F.; writing — review and editing, D.K. and M.F.; visualization, D.K. and M.F.; supervision, M.F.; project administration, M.F.; funding acquisition, M.F. All authors have read and agreed to the published version of the manuscript.

Funding: Part of this research was funded by the JSPS KAKENHI Grant No.16K06309. 
Conflicts of Interest: The authors declare no conflict of interest.

\section{References}

1. Nomura, K.; Ohta, H.; Takagi, A.; Kamiya, T.; Hirano, M.; Hosono, H. Room-temperature fabrication of transparent flexible thin-film transistors using amorphous oxide semiconductors. Nature 2004, 432, 488-492. [CrossRef] [PubMed]

2. Hirao, T.; Furuta, M.; Furuta, H.; Matsuda, T.; Hiramatsu, T.; Hokari, H.; Yoshida, M. 4.1: Distinguished Paper: High Mobility Top-Gate Zinc Oxide Thin-Film Transistors (ZnO-TFTs) for Active-Matrix Liquid Crystal Displays. SID Symp. Dig. Tech. Pap. 2006, 37, 18. [CrossRef]

3. Jiang, J.; Toda, T.; Hung, M.P.; Wang, D.; Furuta, M. Highly stable fluorine-passivated In-Ga-Zn-O thin-film transistors under positive gate bias and temperature stress. Appl. Phys. Express 2014, 7, 114103. [CrossRef]

4. Cho, S.H.; Ryu, M.K.; Kim, H.-O.; Kwon, O.S.; Park, E.-S.; Roh, Y.-S.; Hwang, C.-S.; Park, S.-H.K. Influence of gate dielectric/channel interface engineering on the stability of amorphous indium gallium zinc oxide thin-film transistors. Phys. Status solidi A 2014, 211, 2126-2133. [CrossRef]

5. Wang, D.; Hung, M.P.; Jiang, J.; Toda, T.; Furuta, M. Suppression of Degradation Induced by Negative Gate Bias and Illumination Stress in Amorphous InGaZnO Thin-Film Transistors by Applying Negative Drain Bias. ACS Appl. Mater. Interfaces 2014, 6, 5713-5718. [CrossRef]

6. Koretomo, D.; Toda, T.; Matsuda, T.; Kimura, M.; Furuta, M. Anomalous Increase in Field-Effect Mobility in In-Ga-Zn-O Thin-Film Transistors Caused by Dry-Etching Damage Through Etch-Stop Layer. IEEE Trans. Electron Devices 2016, 63, 2785-2789. [CrossRef]

7. Magari, Y.; Makino, H.; Furuta, M. Carrier Generation Mechanism and Origin of Subgap States in Ar- and He-Plasma-Treated In-Ga-Zn-O Thin Films. ECS J. Solid State Sci. Technol. 2017, 6, Q101-Q107. [CrossRef]

8. Aman, S.G.M.; Magari, Y.; Shimpo, K.; Hirota, Y.; Makino, H.; Koretomo, D.; Furuta, M. Low-temperature $\left(150{ }^{\circ} \mathrm{C}\right)$ activation of $\mathrm{Ar}+\mathrm{O}_{2}+\mathrm{H}_{2}$-sputtered $\mathrm{In}-\mathrm{Ga}-\mathrm{Zn}-\mathrm{O}$ for thin-film transistors. Appl. Phys. Express 2018, 11, 081101. [CrossRef]

9. Kamiya, T.; Hosono, H. Material characteristics and applications of transparent amorphous oxide semiconductors. NPG Asia Mater. 2010, 2, 15-22. [CrossRef]

10. Fortunato, E.; Barquinha, P.; Martins, R. Oxide Semiconductor Thin-Film Transistors: A Review of Recent Advances. Adv. Mater. 2012, 24, 2945-2986. [CrossRef]

11. Raja, J.; Jang, K.; Nguyen, C.P.T.; Yi, J.; Balaji, N.; Hussain, S.Q.; Chatterjee, S. Improvement of Mobility in Oxide-Based Thin Film Transistors: A Brief Review. Trans. Electr. Electron. Mater. 2015, 16, 234-240. [CrossRef]

12. Liao, C. Mobility impact on compensation performance of AMOLED pixel circuit using IGZO TFTs. J. Semicond. 2019, 40, 022403. [CrossRef]

13. Arai, T.; Sasaoka, T. 49.1: Invited Paper: Emergent Oxide TFT Technologies for Next-Generation AM-OLED Displays. SID Symp. Dig. Tech. Pap. 2011, 42, 710-713. [CrossRef]

14. Jang, Y.H.; Kim, D.H.; Choi, W.; Kang, M.-G.; Chun, K.I.; Jeon, J.; Ko, Y.; Choi, U.; Lee, S.-M.; Bae, J.U.; et al. 7-4: Invited Paper: Internal Compensation Type OLED Display Using High Mobility Oxide TFT. SID Symp. Dig. Tech. Pap. 2017, 48, 76-79. [CrossRef]

15. Nomura, K.; Takagi, A.; Kamiya, T.; Ohta, H.; Hirano, M.; Hosono, H. Amorphous Oxide Semiconductors for High-Performance Flexible Thin-Film Transistors. Jpn. J. Appl. Phys. 2006, 45, 4303-4308. [CrossRef]

16. Chong, E.; Chun, Y.S.; Lee, S.Y. Amorphous silicon-indium-zinc oxide semiconductor thin film transistors processed below $150{ }^{\circ} \mathrm{C}$. Appl. Phys. Lett. 2010, 97, 102102. [CrossRef]

17. Kizu, T.; Aikawa, S.; Mitoma, N.; Shimizu, M.; Gao, X.; Lin, M.F.; Nabatame, T.; Tsukagoshi, K. Low-Temperature Processable Amorphous In-WO Thin-Film Transistors with High Mobility and Stability. Appl. Phys. Lett. 2014, 104, 152103. [CrossRef]

18. Koike, K.; Hama, K.; Nakashima, I.; Takada, G.-Y.; Ozaki, M.; Ogata, K.-I.; Sasa, S.; Inoue, M.; Yano, M. Piezoelectric Carrier Confinement by Lattice Mismatch at $\mathrm{ZnO} / \mathrm{Zn}_{0.6} \mathrm{Mg}_{0.4} \mathrm{O}$ Heterointerface. Jpn. J. Appl. Phys. 2004, 43, L1372-L1375. [CrossRef]

19. Taniguchi, S.; Yokozeki, M.; Ikeda, M.; Suzuki, T.-K. Transparent Oxide Thin-Film Transistors Using $\mathrm{n}-\left(\mathrm{In}_{2} \mathrm{O}_{3}\right)_{0.9}\left(\mathrm{SnO}_{2}\right)_{0.1} / \mathrm{InGaZnO}_{4}$ Modulation-Doped Heterostructures. Jpn. J. Appl. Phys. 2011, 50, $04 \mathrm{DF} 11$. [CrossRef] 
20. Jeon, S.; Kim, S.I.; Park, S.; Song, I.; Park, J.; Kim, S.; Kim, C. Low-Frequency Noise Performance of a Bilayer InZnO-InGaZnO Thin-Film Transistor for Analog Device Applications. IEEE Electron Device Lett. 2010, 31, 1128-1130. [CrossRef]

21. Chong, E.; Lee, S.Y. Influence of a highly doped buried layer for HfInZnO thin-film transistors. Semicond. Sci. Technol. 2011, 27, 12001. [CrossRef]

22. Kim, H.-S.; Park, J.S.; Jeong, H.-K.; Son, K.S.; Kim, T.S.; Seon, J.-B.; Lee, E.; Chung, J.G.; Kim, D.H.; Ryu, M.; et al. Density of States-Based Design of Metal Oxide Thin-Film Transistors for High Mobility and Superior Photostability. ACS Appl. Mater. Interfaces 2012, 4, 5416-5421. [CrossRef] [PubMed]

23. Jung, H.Y.; Kang, Y.; Hwang, A.Y.; Lee, C.K.; Han, S.; Kim, D.-H.; Bae, J.-U.; Shin, W.-S.; Jeong, J.K. Origin of the improved mobility and photo-bias stability in a double-channel metal oxide transistor. Sci. Rep. 2014, 4, 3765. [CrossRef]

24. Yang, J.H.; Choi, J.H.; Cho, S.H.; Pi, J.E.; Kim, H.O.; Hwang, C.S.; Park, K.C.; Yoo, S. Highly Stable AlInZnSnO and InZnO Double-Layer Oxide Thin-Film Transistors With Mobility Over $50 \mathrm{~cm}^{2} / \mathrm{V} \cdot \mathrm{s}$ for High-Speed Operation. IEEE Electron Device Lett. 2018, 39, 508-511. [CrossRef]

25. Park, J.C.; Lee, H.-N. Improvement of the Performance and Stability of Oxide Semiconductor Thin-Film Transistors Using Double-Stacked Active Layers. IEEE Electron Device Lett. 2012, 33, 818-820. [CrossRef]

26. Saito, N.; Miura, K.; Ueda, T.; Tezuka, T.; Ikeda, K. High-Mobility and H2-Anneal Tolerant InGaSiO/InGaZnO/InGaSiO Double Hetero Channel Thin Film Transistor for Si-LSI Compatible Process. IEEE J. Electron Devices Soc. 2018, 6, 500-505. [CrossRef]

27. Furuta, M.; Koretomo, D.; Magari, Y.; Aman, S.G.M.; Higashi, R.; Hamada, S.; Hamada, S. Heterojunction channel engineering to enhance performance and reliability of amorphous In-Ga-Zn-O thin-film transistors. Jpn. J. Appl. Phys. 2019, 58, 090604. [CrossRef]

28. Suko, A.; Jia, J.; Nakamura, S.-I.; Kawashima, E.; Utsuno, F.; Yano, K.; Shigesato, Y. Crystallization behavior of amorphous indium-gallium-zinc-oxide films and its effects on thin-film transistor performance. Jpn. J. Appl. Phys. 2016, 55, 35504. [CrossRef]

29. Ide, K.; Nomura, K.; Hiramatsu, H.; Kamiya, T.; Hosono, H. Structural relaxation in amorphous oxide semiconductor, a-In-Ga-Zn-O. J. Appl. Phys. 2012, 111, 073513. [CrossRef]

30. Kim, J.; Bang, J.; Nakamura, N.; Hosono, H. Ultra-wide bandgap amorphous oxide semiconductors for NBIS-free thin-film transistors. APL Mater. 2019, 7, 022501. [CrossRef]

31. Kim, J.; Hiramatsu, H.; Hosono, H.; Kamiya, T. Effects of sulfur substitution in amorphous InGaZnO4: Optical properties and first-principles calculations. J. Ceram. Soc. Jpn. 2015, 123, 537-541. [CrossRef]

32. Kim, J.; Miyokawa, N.; Sekiya, T.; Ide, K.; Toda, Y.; Hiramatsu, H.; Hosono, H.; Kamiya, T. Ultrawide band gap amorphous oxide semiconductor, Ga-Zn-O. Thin Solid Films 2016, 614, 84-89. [CrossRef]

33. Magari, Y.; Hashimoto, S.; Hamada, K.; Furuta, M. Low-Temperature Processed Metal-Semiconductor Field-Effect Transistor with In-Ga-Zn-O/AgOx Schottky Gate. ECS Trans. 2016, 75, 139-144. [CrossRef]

34. Sze, S.M.; Ng, K.K. Physics of Semiconductor Devices, 3rd ed.; Wiley: New York, NY, USA, 2007.

35. Lee, N.H.; Nomura, K.; Kamiya, T.; Hosono, H. Metal-Semiconductor Field-Effect Transistor Made Using Amorphous In-Ga-Zn-O Channel and Bottom Pt Schottky Contact Structure at $200 \mathrm{C}$. ECS Solid State Lett. 2012, 1, Q8-Q10. [CrossRef]

36. Kamiya, T.; Hosono, H. (Invited) Roles of Hydrogen in Amorphous Oxide Semiconductor. ECS Trans. 2013, 54, 103-113. [CrossRef]

37. Jeong, J.; Hong, Y. Debye Length and Active Layer Thickness-Dependent Performance Variations of Amorphous Oxide-Based TFTs. IEEE Trans. Electron Devices 2012, 59, 710-714. [CrossRef]

38. Abe, K.; Sato, A.; Takahashi, K.; Kumomi, H.; Kamiya, T.; Hosono, H. Mobility- and temperature-dependent device model for amorphous In-Ga-Zn-O thin-film transistors. Thin Solid Films 2014, 559, 40-43. [CrossRef]

39. Kamiya, T.; Nomura, K.; Hosono, H. Origins of High Mobility and Low Operation Voltage of Amorphous Oxide TFTs: Electronic Structure, Electron Transport, Defects and Doping. J. Disp. Technol. 2009, 5, 273-288. [CrossRef] 
40. Kim, Y.; Bae, M.; Kim, W.; Kong, D.; Jung, H.K.; Kim, H.; Kim, S.; Kim, D.M.; Kim, D.H. Amorphous InGaZnO Thin-Film Transistors-Part I: Complete Extraction of Density of States Over the Full Subband-Gap Energy Range. IEEE Trans. Electron Devices 2012, 59, 2689-2698. [CrossRef]

41. Kim, S.; Jeon, Y.W.; Kim, Y.; Kong, D.; Jung, H.K.; Bae, M.-K.; Lee, J.-H.; Du Ahn, B.; Park, S.Y.; Park, J.-H.; et al. Impact of Oxygen Flow Rate on the Instability Under Positive Bias Stresses in DC-Sputtered Amorphous InGaZnO Thin-Film Transistors. IEEE Electron Device Lett. 2011, 33, 62-64. [CrossRef]

(C) 2020 by the authors. Licensee MDPI, Basel, Switzerland. This article is an open access article distributed under the terms and conditions of the Creative Commons Attribution (CC BY) license (http://creativecommons.org/licenses/by/4.0/). 